\title{
Paroxetine Mesylate
}

National Cancer Institute

\section{Source}

National Cancer Institute. Paroxetine Mesylate. NCI Thesaurus. Code C47653.

The mesylate salt form of paroxetine, a phenylpiperidine derivative and a selective serotonin reuptake inhibitor (SSRI) with antidepressant and anxiolytic properties.

Paroxetine binds to the pre-synaptic serotonin transporter complex resulting in negative allosteric modulation of the complex, thereby blocking reuptake of serotonin by the presynaptic transporter. Inhibition of serotonin recycling enhances serotonergic function through serotonin accumulation in the synaptic cleft, which resulting in long-term desensitization and downregulation of 5HT1 (serotonin) receptors and leading to symptomatic relief of depressive illness. 